\title{
Irrigation fluids used for transurethral resection of the prostate: a double-edged sword
}

\author{
Hee-Pyoung Park \\ Department of Anesthesiology and Pain Medicine, Seoul National University Hospital, Seoul National University \\ College of Medicine, Seoul, Korea
}

\begin{abstract}
Large volumes of irrigation fluids are commonly used for distension and irrigation of the bladder during transurethral resection of the prostate (TURP). During the surgical procedure, exposure of venous sinuses and injury to the prostatic capsule lead to systemic absorption of irrigation fluids, resulting in several complications including fluid overload, pulmonary edema, congestive heart failure, hyponatremia, and hypothermia. Furthermore, specific additives such as glycine and sorbitol have adverse effects. Glycine has toxic effects on the heart and the kidneys. The absorbed glycine is metabolized to ammonia in the liver. The hyperammonemia may cause neurologic complications such as tremors and seizures. Massive absorption of sorbitol can also cause hyperglycemia and lactic acidosis [1].

Another important complication resulting from massive systemic absorption of irrigation fluids is coagulopathy. An in vitro study conducted by Shin et al. [2], published in this issue of the Korean Journal of Anesthesiology, investigated the effect of irrigation using a sorbitol-mannitol mixture on coagulation using rotational thromboelastometry (ROTEM) at different levels of hemodilution. They demonstrated that increasing hemodilution
\end{abstract}

resulted in impaired coagulation. Interference with clot stabilization with fibrin polymerization may be responsible for the impairment of coagulation. A decrease in the serum level of coagulation factors due to hemodilution may also lead to impaired coagulation during TURP [3]. Considering these factors, the coagulation status should be checked if a large volume of irrigation fluid is used with a likelihood of significant systemic absorption. Besides, intraoperative hemorrhage may also contribute to consumption coagulopathy.

In conclusion, it is important for anesthesiologists to be aware of complications resulting from the systemic absorption of irrigation fluids during TURP. ROTEM as a point-of-care tool may be helpful in the assessment of clotting function and early detection of a coagulopathic state when massive absorption of irrigation fluids accompanied by intraoperative hemorrhage is suspected.

\section{Conflicts of Interest}

No potential conflict of interest relevant to this article was reported.

\section{References}

1. Trépanier CA, Lessard MR, Brochu J, Turcotte G. Another feature of TURP syndrome: hyperglycaemia and lactic acidosis caused by massive absorption of sorbitol. Br J Anaesth 2001; 87: 316-9.

Corresponding author: Hee-Pyoung Park, M.D., Ph.D.

Department of Anesthesiology and Pain Medicine, Seoul National University Hospital, Seoul National University College of Medicine, 101 Daehak-ro, Jongno-gu, Seoul 03080, Korea

Tel: 82-2-2072-2466, Fax: 82-2-747-5639, Email: hppark@snu.ac.kr

ORCID: https://orcid.org/0000-0002-4772-0780

Received: February 27, 2019. Accepted: February 28, 2019.

Korean J Anesthesiol 2019 April 72(2): 87-88

https://doi.org/10.4097/kja.19078

(c) This is an open-access article distributed under the terms of the Creative Commons Attribution Non-Commercial License (http://creativecommons.org/ licenses/by-nc/4.0/), which permits unrestricted non-commercial use, distribution, and reproduction in any medium, provided the original work is properly cited. 
2. Shin $\mathrm{H}$, Lee $\mathrm{H}, \mathrm{Na} \mathrm{H}$. The effect of a mixture of $2.7 \%$ sorbitol- $0.54 \%$ mannitol solution on blood coagulation: an in-vitro, observational healthy-volunteer study using rotational thromboelastometry (ROTEM). Korean J Anesthesiol 2019; 72: 143-9.

3. Shin HJ, Na HS, Jeon YT, Park HP, Nam SW, Hwang JW. The impact of irrigating fluid absorption on blood coagulation in patients undergoing transurethral resection of the prostate: a prospective observational study using rotational thromboelastometry. Medicine (Baltimore) 2017; 96: e5468. 